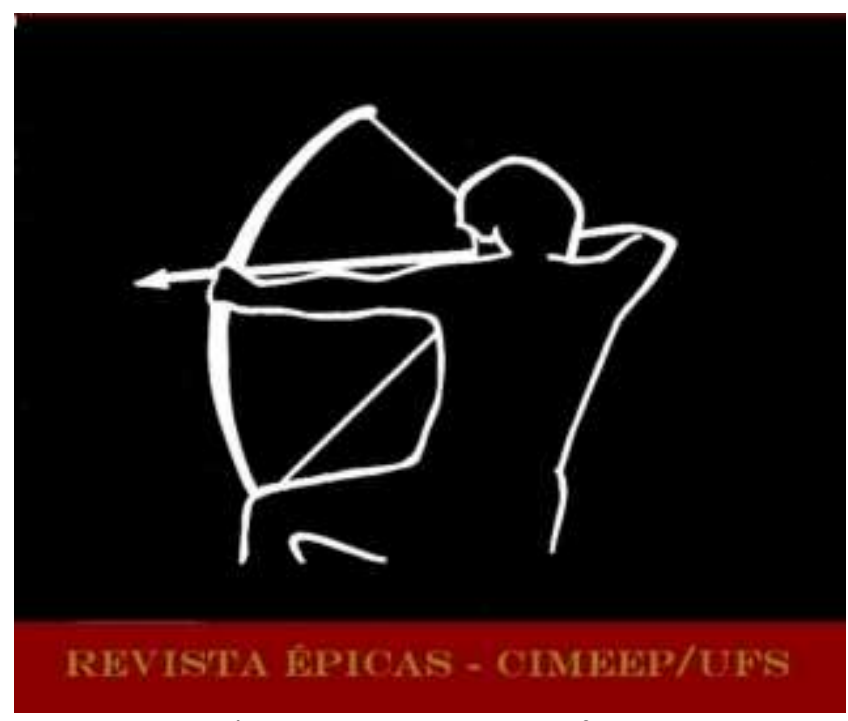

FUENTES, Juan Héctor. Una nota sobre las referencias a las aves de caza en el Tapiz de Bayeux y su relación con el Cantar de Mio Cid. In: Revista Épicas. Ano 5, N. 9, Jun 2021, p. 123-132. ISSN 2527080-X. DOI: http://dx.doi.org/10.47044/2527-080X.2021v9123132

\title{
UNA NOTA SOBRE LAS REFERENCIAS A LAS AVES DE CAZA EN EL TAPIZ DE BAYEUX Y SU RELACIÓN CON EL CANTAR DE MIO CID
}

\author{
UMA NOTA SOBRE AS REFERÊNCIAS ÀS AVES DE CAÇA NA TAPEÇARIA DE BAYEUX \\ E SUA RELAÇÃO COM O CANTAR DE MIO CID
}

Juan Héctor Fuentes ${ }^{1}$

IIBICRIT - CONICET

UBA

RESUMEN: En el presente trabajo realizamos un estudio comparativo de las imágenes vinculadas con la cetrería en el Tapiz de Bayeux y en el Cantar de Mio Cid. En primer lugar analizamos las imágenes del tapiz en las que aparecen aves de caza: la representación de las mismas nos sitúa en un entorno nobiliario en el que simbolizan tanto el ocio estamental como, en sentido derivado, las intenciones de paz y concordia en las relaciones diplomáticas. Posteriormente un análisis contrastivo con la secuencia bélica de tapiz nos permite señalar que la exclusión de las aves de caza de la seccción se justifica por la no adecuación de las mismas a la actividad guerrera. En seguida, luego de comparar las observaciones realizadas sobre el tapiz con la ausencia marcada de las aves al comienzo del Cantar, llegamos a la conclusión de que dicha ausencia sugiere no solo la clausura del ocio estamental para el Cid, sino también la ruptura de las negociaciones diplomáticas y el comienzo de su actividad guerrera.

Palabras-claves: Cetrería medieval; Tapiz de Bayeux; Cantar de Mio Cid

RESUMO: No presente trabalho realizamos um estudo comparativo das imagens relacionadas com a falcoaria na Tapeçaria de Bayeux e no Cantar de Mio Cid. Em primeiro lugar, analisamos as imagens da tapeçaria em que aparecem as aves de caça: sua representação nos situa em um ambiente nobre, em que simbolizam tanto

${ }^{1}$ Miembro del GT 5 del CIMEEP. ORCID: ttps://orcid.org/0000-0002-1264-3586. 
o ócio da nobreza como, em sentido derivado, as intenções de paz e concórdia nas relações. Posteriormente, uma análise contrastiva com a sequência bélica da tapeçaria permite apontar que a exclusão das aves de caça da seção se justifica pela não adequação das mesmas à atividade guerreira. Em seguida, depois de comparar as observações realizadas sobre a tapeçaria com a ausência marcante dos pássaros no início do Cantar, chegamos à conclusão de que tal ausência sugere não só o fechamento do ócio da classe nobre para o Cid, mas também o rompimento das negociações diplomáticas e o início de sua atividade bélica.

Palavras-chave: Falcoaria medieval; Tapeçaria de Bayeux; Cantar de Mio Cid

\section{Introducción}

En un trabajo anterior (Fuentes 2007) nos propusimos revisar la interpretación de los versos 3-5 del Cantar de Mio Cid en el que son mencionadas aves de caza (Vio puertas abiertas e uços in cañados, / alcándaras vazías, sin pielles e sin mantos, / e sin falcones e sin adtores mudados). Como resultado de nuestro estudio llegamos a la conclusión de que la mención de dichas aves en el comienzo del cantar nos sitúa en el entorno exclusivo de la nobleza y, por su valor simbólico, su ausencia nos habla tanto de la clausura del tiempo de ocio nobiliario como de una situación de privación en lo que respecta al honor del Cid. Como bien señala Montaner, el verso es parte de una escena que "recrea un 'escenario de ausencias' que sugiere el desamparo, el desarraigo y la desprotección en la que quedan el Cid, su familia y su mesnada" (2011: 647). Asimismo la omisión de referencias cetreras en el resto del Cantar nos remitirían a una construcción del héroe según un modelo caballeresco más espiritualizado promovido por órdenes religiosas como Cluny y el Císter, en el cual la cetrería es considerada una práctica reprobable (Fuentes 2007: 167-168).

\section{La presencia de aves de caza en el Tapiz de Bayeux}

Fuera del ámbito peninsular encontramos un testimonio sumamente relevante que nos permite realizar un paralelismo con el Cantar de Mio Cid en lo que respecta a la relación entre las aves de caza y la guerra y a sus significaciones en el estamento nobiliario: se trata del célebre Tapiz de Bayeux, que relata la conquista de Inglaterra por el duque Guillermo, más tarde apodado "El Conquistador". Los historiadores coinciden en fechar la confección de la obra no mucho después de 1066, quizás en Canterbury, a instancias de algún patrocinador normando, quizás el hermanastro de Guillermo, Odón, obispo de Bayeux. ${ }^{2}$ En nuestro análisis comparativo nos focalizaremos en las aves que son representadas en la banda central del tapiz. ${ }^{3}$

\footnotetext{
2 Véanse Brilliant (1997: 111) y Spiezia (2009: 42-52).

3 Por la complejidad de interpretación dejamos de lado las bandas inferior y superior del tapiz que aportan una interpretación moralizante de los hechos narrados en la banda central. Para el simbolismo de las mismas, véase Rubio Tovar (2003).
} 


\subsection{Aves y diplomacia en el Tapiz de Bayeux}

La primera imagen del tapiz (escena 1: EDWARD REX ${ }^{4}$ ) nos presenta al anciano rey Eduardo, coronado y con cetro, dando instrucciones y enviando al conde Harold Godwinson en una misión diplomática dirigida al conde Guillermo de Normandía, primo del monarca, con el fin de asegurar la sucesión del trono de Inglaterra (figura 1). A continuación (escena 2: VBI HAROLD DVX ANGLORVM ET SVI MILITES EQVITANT AD BOSHAM ${ }^{5}$ ) Harold es representado a caballo rumbo a su señorío en Bosham, rodeado de servidores, perros y, lo que nos interesa de modo particular, portando un ave de caza en su brazo izquierdo (figura 2). Luego de implorar la bendición divina en una Iglesia y de tener un festejo con los suyos en lo que parece su casa señorial de Bosham, Harold se embarca hacia Normandía portando nuevamente un halcón junto con un servidor que lleva sus perros (escena 4: HIC HAROLD MARE NAVIGAVIT') (figura 3).

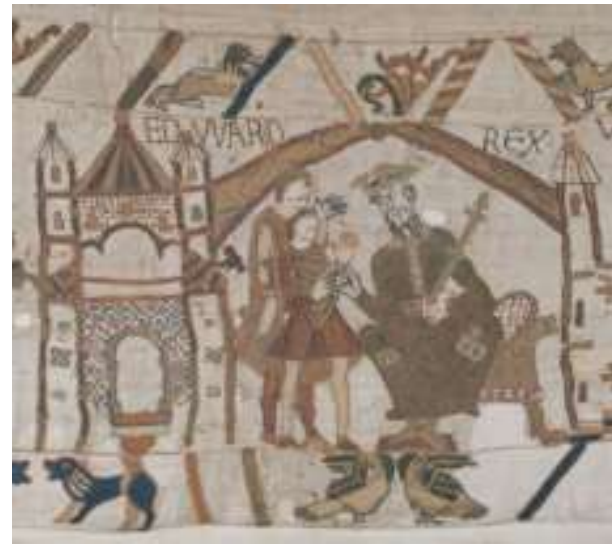

Figura 1

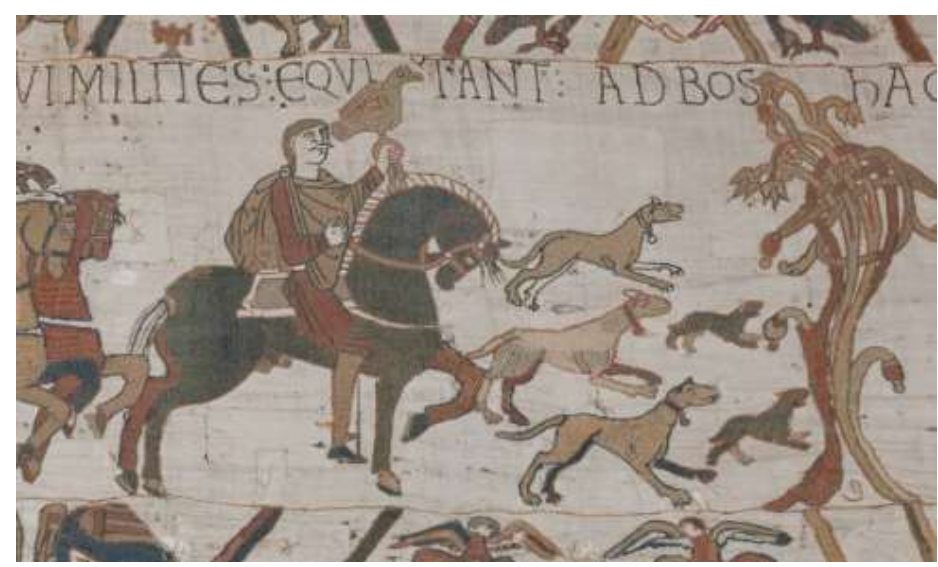

Figura 2

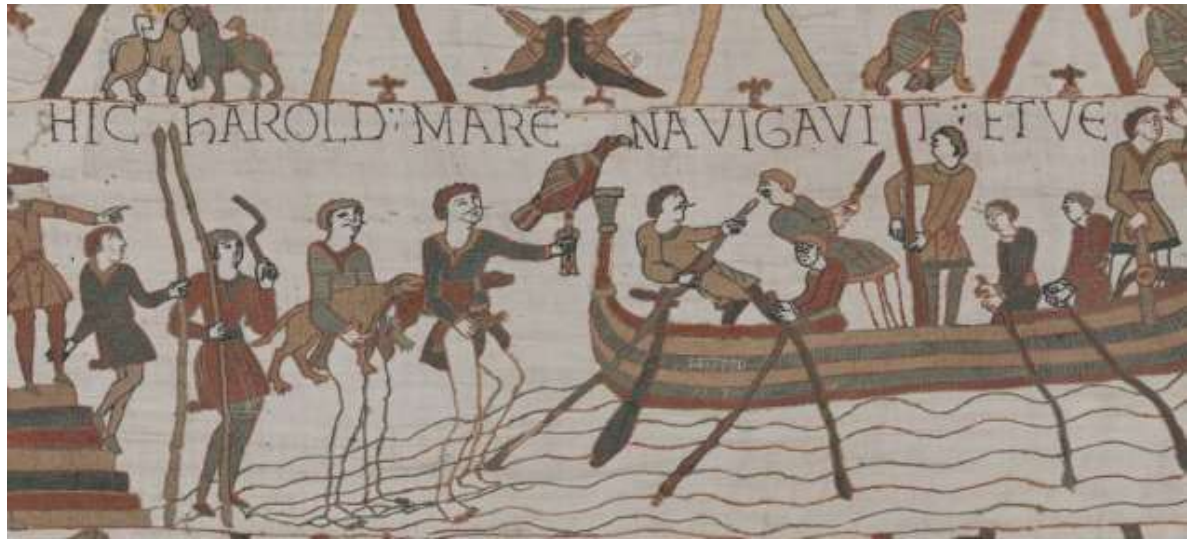

\footnotetext{
4 "Rey Eduardo". La numeración de las escenas corresponde a la que figura en el tapiz. Véase Bertrand (1966: 75-115). Las traducciones del latín son nuestras.

5 "Donde Harold, duque de los ingleses, y sus soldados cabalgan hacia Bosham."

6 "Aquí Harold navega sobre el mar."
} 
Figura 3

En su travesía por el Canal de la Mancha el viento desvía las naves inglesas y las lleva hasta las costas de Ponthieu, una pequeña provincia al Norte de Normandía, donde es apresado por el conde Guy, vasallo de Guillermo (escena 7: HIC APPREHENDIT WIDO HAROLDV $<M>^{7}$ ). A continuación (escena 8: ET DUXI EVM AD BELREM ET IBI TENVIT ${ }^{8}$ ) el conde de Ponthieu conduce a Harold a su palacio de Beaurain: ambos nobles portan sus azores y son seguidos por hombres armados y perros (figura 4).

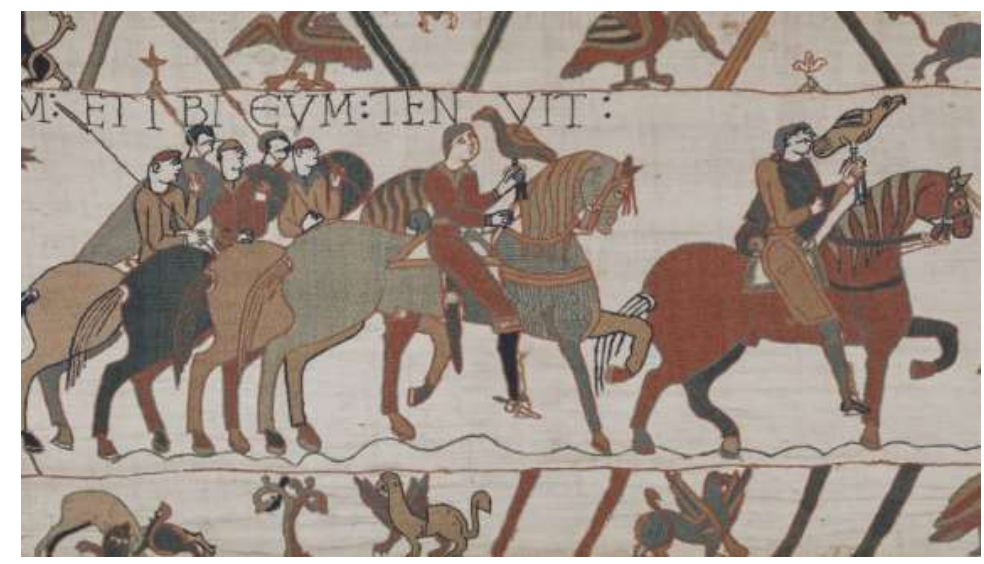

Figura 4

Las aves de caza vuelven a aparecer en la escena 13, en la que Guy conduce a Harold ante

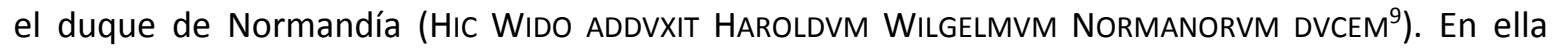
podemos observar al conde Ponthieu vestido de manto, con un halcón sobre al brazo, señalando a Harold en presencia de su señor (figura 5). En contraste con la escena 8, la figura de Harold es tratada con mayor respeto: el noble aparece ricamente vestido con un manto y sostiene también un azor.

\footnotetext{
7 "Aquí Guy aprisiona a Harold."

8 "Y lo conduce a Beaurain y allí lo retiene."

9 "Aquí Guy conduce a Harold en presencia de Guillermo, duque de los normandos."
} 


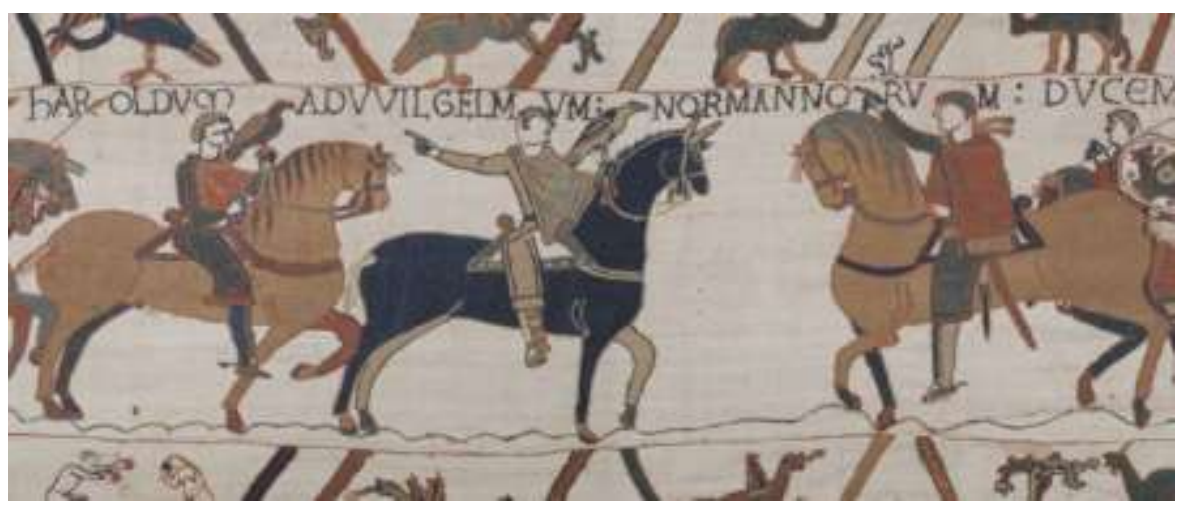

Figura 5

La última escena del bordado central del tapiz en la que aparecen aves de caza es la 14 (HIC DUX WILGELM CVM HAROLDO VENIT AD PALATIV $<M>S V V<M>^{10}$ ) en la que Guillermo, precedido por perros, ricamente vestido y nuevamente con un azor en su mano derecha, conduce a Harold a su palacio de Rouen (figura 6). La escena se cierra con la imagen del noble inglés, en el interior del palacio, dirigiendo la palabra a Guillermo, representado en un trono con su espada apoyada en el piso.

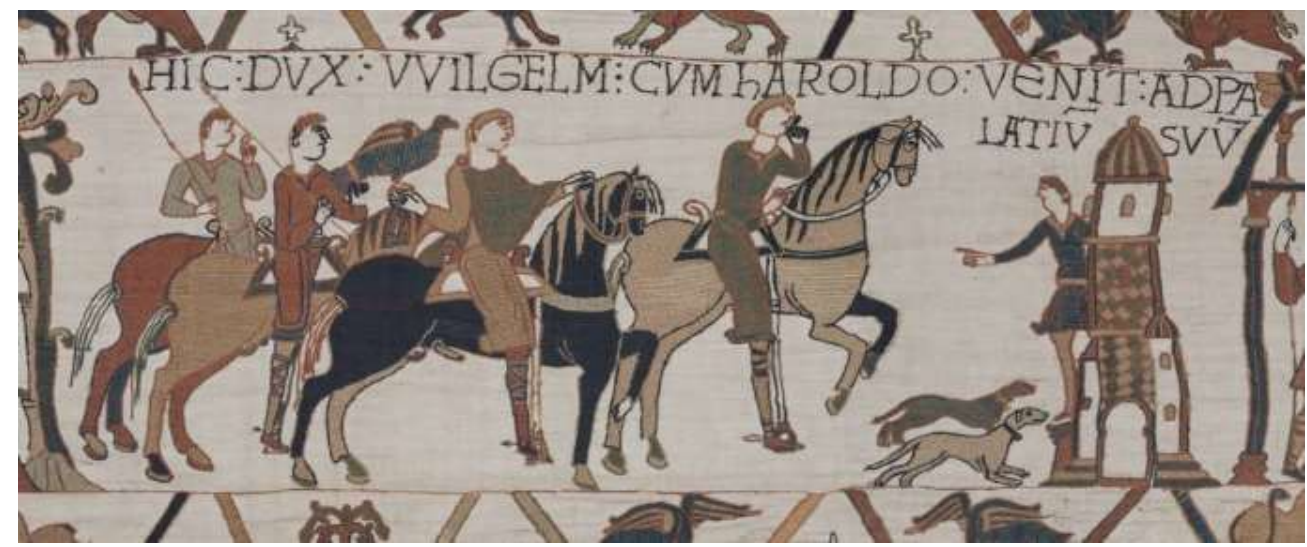

Figura 6

\subsection{Las aves de caza como símbolo de propósitos pacíficos}

Como señala Van Den Abeele (1990: 37), citando a Benoist, en su estudio sobre la halconería en la literatura francesa de los siglos XII a XIV, las aves cetreras estuvieron asociadas a las relaciones diplomáticas y a la concordia entre nobles, entre otros motivos, por el hecho de no exigir el empleo de ningún arma en su ejercicio, a diferencia de la caza mayor, más cercana a la forma de la guerra. Así las aves de caza, halcones o azores, que acompañan a mensajeros y embajadores deben ser

\footnotetext{
10 "Aquí el duque Guillermo llega a su palacio con Harold."
} 
interpretadas como signo de intenciones pacíficas, de recibimiento y hospitalidad. Las mismas se cuentan con frecuencia entre las listas de presentes y regalos. ${ }^{11}$

El simbolismo que Van Den Abeele encuentra en los textos literarios franceses se aplica perfectamente a las imágenes se la sección inicial del Tapiz de Bayeux. Oggins (2004: 47-48) señala que las imágenes que presentan a Harold con aves de caza no dan a entender el gusto del noble inglés por la cetrería, como sostuvieron algunos, sino el carácter diplomático de su misión, y que los azores y perros que aparecen en el tapiz serían presentes para Guillermo, de quien sabemos era un aficionado de la cetrería. ${ }^{12}$ Asimismo la imagen de la escena 14 (figura 6), en la que aparece Guillermo a caballo con un azor sobre su mano, sería símbolo de la aceptación y de la hospitalidad del duque normando hacia su visitante anglosajón. Como bien expone Spiezia:

Nel contesto dell'arazzo il gesto di Aroldo si presta ad essere letto come un dono 'nobile' fra 'nobili', un gesto politico, con un intento pacifico, che prefigura accordi di natura diplomatica. Dal punto di vista di Guglielmo ricevere il dono esprime benevolenza verso il suo messaggero (2009, p. 60).

Con el inicio de las acciones bélicas las aves de caza dejan de ser representadas en la franja central del tapiz. Harold participa heroicamente en la campaña que Guillermo emprende contra el conde Conan II de Bretaña, por lo que el conde de Normandía le entrega las armas, entablándose así entre ellos un vínculo de vasallaje (escenas 16 a 21). En Bayeux Harold jura fidelidad a Guillermo y retorna a Inglaterra (escenas 22 a 25). A la muerte de Eduardo, a pesar de su juramento, Harold es coronado (escenas 26 a 33). La noticia llega a Normandía: luego de varios meses de preparación, Guillermo, al frente de unos 7000 hombres invade Inglaterra, y en la batalla de Hastings (14 de octubre de 1066) derrota y da muerte a Harold (escenas 34 a 57). En toda esta secuencia de escenas apretadamente resumida no encontramos ninguna referencia a las aves de caza.

Si comparamos las escenas 2-5, mencionadas anteriormente, que describen la partida de Harold hacia Bosham y el inicio de su misión diplomática, con las escenas 35-38, que nos presentan la preparación de las naves de Guillermo, advertiremos un notable contraste: mientras que en la primera secuencia Harold y sus hombres se embarcan con animales de caza (azores y perros), en la segunda los elementos que el ejército transporta a las naves son solo los propios de una expedición

\footnotetext{
11 Véase Van Den Aveele (1990: 37-40).

12 Spiezia (2009: 61-63) identifica las aves de caza que aparecen en la banda central del tapiz con accipítridos, específicamente azores, y señala que, si bien el azor (accipiter gentilis) era considerado socialmente inferior al halcón, dicha distinción no habría sido válida entre los anglosajones.
} 
militar: víveres -entre los que el tapiz destaca el vino-, armamento (nótese cómo son llevadas las cotas de malla) y, como se evidencia en la escena 39 (HIC EXEVNT CABALLI DE NAVIBVS ${ }^{13}$ ), caballos (figuras 7 y 8). La exclusión de aves de caza entre los elementos embarcados se justifica por la no pertinencia de las mismas a la actividad bélica.

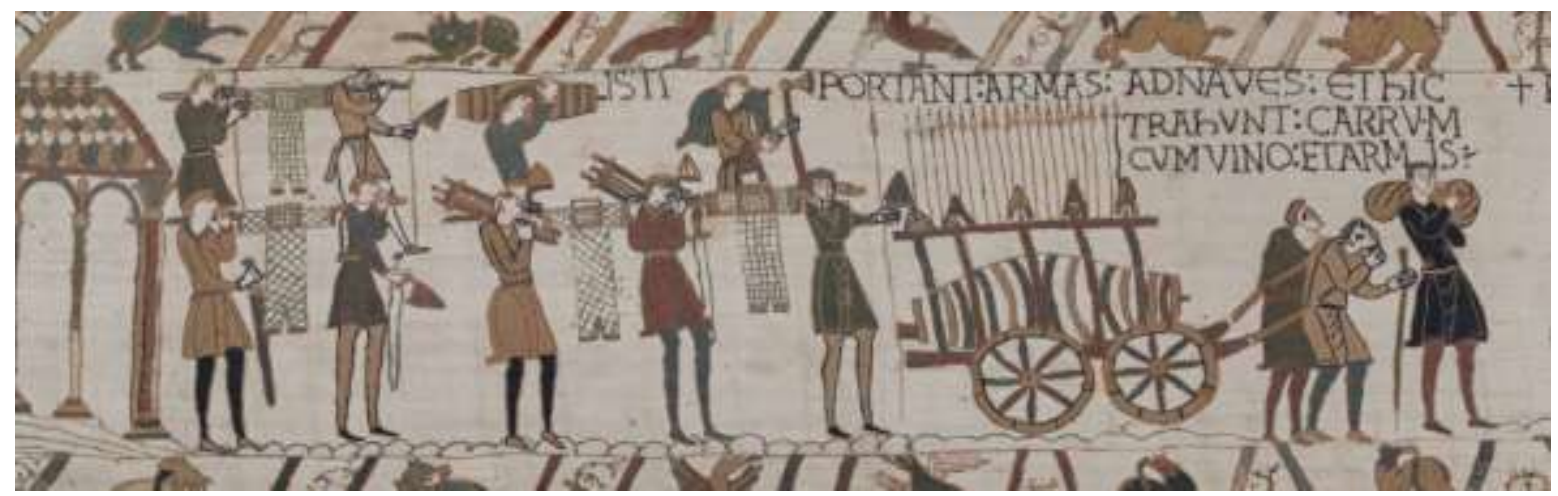

Figura 7

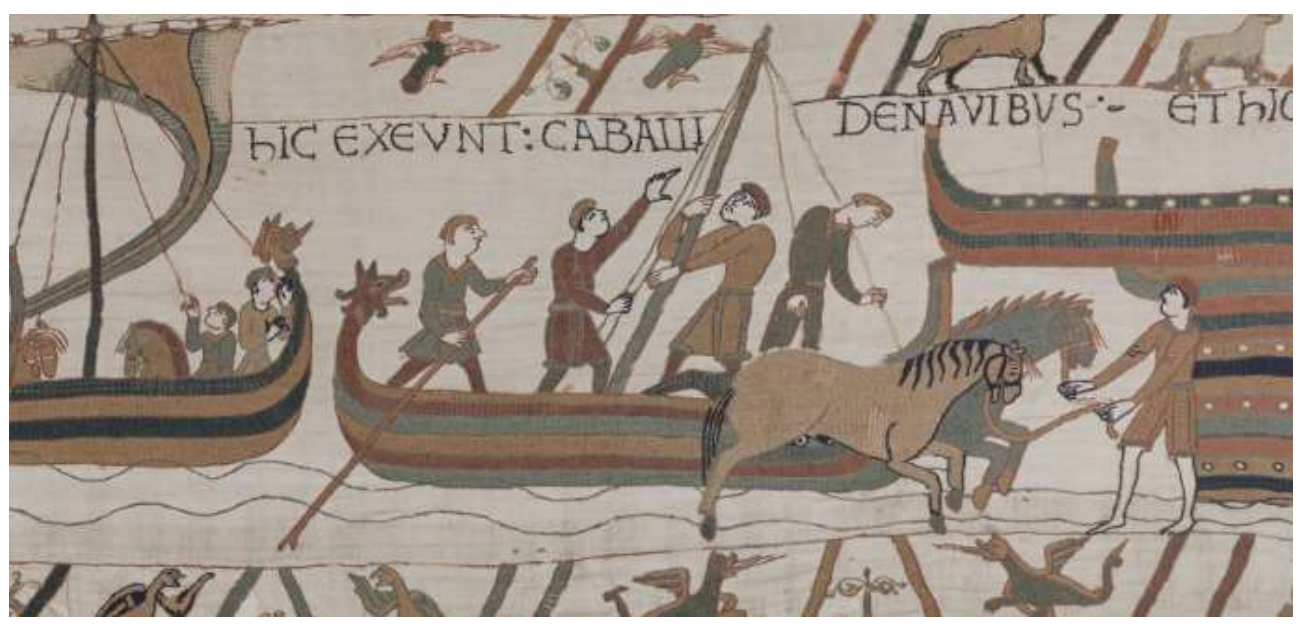

Figura 8

\section{El Tapiz de Bayeux y el Cantar de Mio Cid: contrastes y coincidencias}

A pesar de la distancia temporal entre el tapiz y el Cantar de Mio Cid es posible advertir un universo simbólico común que habilita un estudio comparativo de ambas obras.

En lo que respecta a presencia de aves de caza, las dos obras nos ubican en un entorno eminentemente aristocrático. Si tenemos en cuenta su simbolismo relacionado con las actividades

13 "Aquí salen los caballos de las naves." 
diplomáticas, la hospitalidad y la concordia, como hemos visto en las primeras escenas del tapiz, con la ausencia marcada de las mismas al comienzo del Cantar se vería representada no solo la clausura del ocio estamental del Cid, como sostuvimos en un estudio anterior (Fuentes 2007), sino también la pérdida del amor del rey, el estado de indefensión del Cid por la aplicación de la ira regia, y asimismo la negación de cualquier via de negociación: "Ya lo vee el Cid, que del rey non avié gracia" nos dice el v. 50 del primer cantar cuando el héroe entra en Burgos y se encuentra con las puertas de la ciudad cerradas. ${ }^{14}$

En lo que respecta a las escenas 35-37 del tapiz, de carácter eminentemente militar, los preparativos de la hueste de Guillermo nos recuerdan, mutatis mutandis, los del Cid en el momento de su partida hacia el destierro. Así como el tapiz describe el embarque de armas, caballos y víveres, el Cantar nos presenta la preocupación del Campeador por obtener provisiones, conducho. ${ }^{15}$ No habiendo podido comprarlas en Burgos por disposición del rey, será Martín Antolínez quien se las suministre: ${ }^{16}$

Martín Antolínez, el burgalés conplido,

a mio Cid e a los suyos, abástales de pan e de vino;

non lo conpra, ca él se lo avié consigo,

de todo conducho bien los ovo bastidos. (vv. 65-68)

Como se puede apreciar, tanto en el relato del tapiz como en el del Cantar no hay lugar para elementos propios del ocio nobiliario como lo son los halcones y azores. ${ }^{17}$

\section{Conclusión}

A través de nuestro breve estudio podemos llegar a la conclusión de que tanto en el tapiz de Bayeux como en el Cantar de Mio Cid las aves de caza nos sitúan en un marco netamente aristocrático en el que simbolizan el ocio nobiliario y, como derivación de este sentido, las intenciones de paz y de concordia en las relaciones diplomáticas. Como consecuencia, la ausencia

\footnotetext{
14 Para el cocepto de ira regia y su aplicación remito a Montaner (2011: 636). La Historia Roderici resalta la negación de cualquier instancia diplomática cuando señala: Rex autem uehementer contra illos iratus suam exconditionen licet iustissimam non solum ei accipere uerum etiam benigne audire noluit (HR, 34, 36-38, ed. Falque Rey, 1990) ["El rey, vehementemente airado con ellos los [los mensajeros del Cid], no solo no quiso recibir su excusación, aunque era justísima, sino que ni siquiera accedió a oirla benignamente"] (trad. Falque Rey, 1983: 353).

15 El término conducho remite a la "provisión de comida, bastimento" que se da al que está de viaje" (Menéndez Pidal (1944-1946, III: 578).

${ }^{16}$ Adviértase la relevancia que en ambas obras se da al vino.

${ }^{17}$ La comparación con el Tapiz de Bayeux nos aporta un argumento más en contra de la idea de que el Cid hubiera llevado consigo aves de caza para proveerse de alimentos durante el destierro.
} 
marcada de las mismas sugiere junto con la clausura del ocio estamental, la ruptura de la concordia y de las relaciones diplomáticas y, en ambas obras, el comienzo de la actividad bélica de los nobles. La guerra exige la total atención del caballero, más si es en defensa de la Cristiandad, como se deja traslucir en en el Cantar de Mio Cid. La cetrería sería en consecuencia una práctica incompatible con ella. Como afirmaba Eugenio III en la carta de convocatoria para la segunda cruzada según nos la transmite Otto de Friesing en su Gesta Friedirici Imperatori $(\mathrm{I}, 36)$ :

\begin{abstract}
Además, porque aquellos que militan para el Señor en modo alguno deben prestar atención a los vestidos preciosos ni al cultivo de la belleza externa ni a los perros o los azores o a cualquier otra cosa que implique disolución, exhortamos en el Señor a vuestra prudencia a que quienes se propusieron realizar tan santa obra no se preocupen por esas cuestiones, antes bien con todas su fuerzas apliquen su atención y diligencia en las armas, en los caballos y en las restantes cosas con las que puedan vencer a los infieles. (ed. Waitz, 1912: 57) $)^{18}$
\end{abstract}

\title{
Referencias bibliográficas
}

BERTRAND, S. La tapisserie de Bayeux et la manière de vivre au onzième siècle. La Pierre qui Viré: Zodiaque, 1966.

BRILLIANT, R. (1997) The Bayeux Tapestry: a stripped narrative for their eyes and ears. In: GAMESON, R. (ed.) The Study of the Bayeux Tapestry. Woodbridge: The Boydell Press, 1997, p. 111137.

DODWELL, C. R. The Bayeux Tapestry and the French Secular Epic. In: The Burlington Maga zine, vol. 108, 1966, no 764: 549-560.

FALQUE REY, E. (ed.) (1990) Historia Roderici. In: FALQUE, E., GIL, J., MAYA, A. (eds.) Chronica Hispana saeculi XII. Pars I. Brepols: Turnhout, 1990, p. 3-98.

FALQUE REY, E. Traducción de la Historia Roderici. In: Boletín de la Institución Fernán González, 201, 1983, p.339-375

FUENTES, J. H. Sin falcones e sin adtores mudados': la cetrería en el Cantar de Mio Cid. In: Olivar, 8, 10, 2007, p. 157-170.

MONTANER, A. (ed.) Cantar de Mio Cid. Madrid-Barcelona: Real Academia Española-Galaxia Gutenberg-Círculo de Lectores, 2011.

OGGINS, R. S. The Kings and Their Hawks. Falconry in Medieval England. New Haven \& London, Yale University Press, 2004.

18 Praeterea, quoniam illi qui Domino militant nequaquam in vestibus preciosis nec cultu formae nec canibus vel accipitribus vel aliis quae portendant lasciviam debent intendere, prudentiam vestram in Domino commonemus, ut, qui tam sanctam opus incipere decreverint, ad haec non intendant, sed in armis, equis et caeteris, quibus infideles expugnent, totis viribus studium et diligentiam adhibeant $(I, 36)$. 
OWEN-CROCKER, G. R. Squawk talk: commentary by birds in the Bayeux Tapestry?. In: Anglo-Saxon England, 34, 2005, p. 237-254.

RUBIO TOVAR, J. Las fábulas del Tapiz de Bayeux. In: Revista de poética medieval, 11, 2003, p. 93125.

SPIEZIA, A. (2009) “La falconería nell'Inghilterra anglosassone”, ArNoS, 2, 2009, p. 29-60.

VAN DEN ABEELE, B. La Fauconnerie dans les lettres françaises du XII ${ }^{\mathbf{e}}$ au XIV ${ }^{\mathbf{e}}$ siècle. Leuven: University Press, 1990.

WAITZ, G. (ed.). Ottonis et Rahewini, Gesta Friederichi I. Imperatori. Hannoverae et Lipsiae: Impensis Bibliopolii Hahniani, 1912.

WILSON, D. M. The Bayeux Tapestry. London: Thames \& Hudson, 2004. 